\title{
A Conceptual Analysis of Personality Traits, Emotional Intelligence and Customer-Oriented Behaviour among Malaysian Nursing Students
}

Aervina Misron, Ong Choon Hee

To Link this Article: http://dx.doi.org/10.6007/IJARBSS/v11-i1/8475

DOI:10.6007/IJARBSS/v11-i1/8475

Received: 11 November 2020, Revised: 03 December 2020, Accepted: 24 December 2021

Published Online: 17 January 2021

In-Text Citation: (Misron \& Hee, 2021)

To Cite this Article: Misron, A., \& Hee, O. C. (2021). A Conceptual Analysis of Personality Traits, Emotional Intelligence and Customer-Oriented Behaviour among Malaysian Nursing Students. International Journal of Academic Research in Business and Social Sciences, 11(1), 276-295.

Copyright: @ 2021 The Author(s)

Published by Human Resource Management Academic Research Society (www.hrmars.com)

This article is published under the Creative Commons Attribution (CC BY 4.0) license. Anyone may reproduce, distribute, translate and create derivative works of this article (for both commercial and non-commercial purposes), subject to full attribution to the original publication and authors. The full terms of this license may be seen

at: http://creativecommons.org/licences/by/4.0/legalcode

Vol. 11, No. 1, 2021, Pg. 276 - 295

Full Terms \& Conditions of access and use can be found at http://hrmars.com/index.php/pages/detail/publication-ethics 


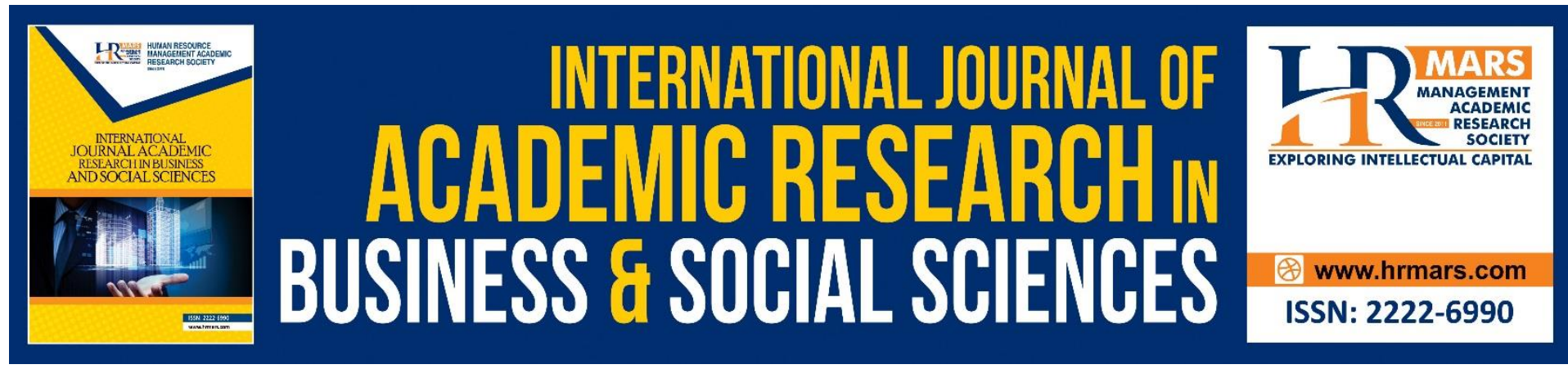

\title{
A Conceptual Analysis of Personality Traits, Emotional Intelligence and Customer-Oriented Behaviour among Malaysian Nursing Students
}

\author{
Aervina Misron, Ong Choon Hee \\ Azman Hashim International Business School, Universiti Teknologi Malaysia, Johor, Malaysia. \\ Email: aervina64@gmail.com
}

\begin{abstract}
Recently, healthcare sector is facing increasing challenges and growing expectations from the patients. Ministry of Health Malaysia received increasing number of complaints for public hospitals on unsatisfied service quality which involved nursing services. Satisfaction with nursing services has been reported to contribute more significantly than any other service to overall perceptions of healthcare service quality. Researchers reported the new generation of nursing graduates were being criticized for their dissatisfactory attitudes towards patients and deterioration in the standard service delivery performance which has been identified as the contributing factors to the increasing number of complaints and criticisms on nurses. Customer-oriented behaviour has been validated as an essential approach to achieve higher quality of care and improving patients' satisfaction with the healthcare service delivered. Owing to that fact, this paper aims to impart a conceptual analysis of the mediating effects of emotional intelligence on the relationship between big five personality traits and customeroriented behaviour among Malaysian nursing students. This paper is guided by trait theory and emotional intelligence theory in establishing the proposed theoretical framework. Our conceptual analysis suggests that emotional intelligence significantly mediates the relationship between big five personality traits and customer-oriented behaviour. In addition, this study provides an avenue to researchers to examine nursing students' customer-oriented behaviour level and its relationship with big five personality traits and emotional intelligence. It also offers a beneficial guideline for Student Recruitment Department of nursing colleges to enrol the best candidates with the right personality traits into the nursing program and lead towards the sustainability of nursing care quality deliver by the future nurses.

Keywords: Customer-Oriented Behaviour, Personality Traits, Emotional Intelligence, Nursing Students, Healthcare.
\end{abstract}

\section{Introduction}

Healthcare is a critical service environment due to the unforeseeable circumstances, demanding patients, workload and organizational complexity (Bruno, Dell'Aversana and Zunino, 2017). Healthcare services are intangible product. It cannot physically be touched, counted, measures, sensed or viewed like manufactured goods (Tam, 2007). Healthcare services rely on the service process, customer and service provider engagement and often 
require patient to be involved in the process (Tam, 2007). The engagement between the patient and the healthcare provider typically included interactions and extensive communication (Tam, 2007). Patients are unable to properly assess the value of medical treatment technologies and tend to rely on behaviours and interpersonal interactions as a measure of assessment (Yoon, Choi and Park, 2007). The interpersonal interactions of service providers with patients is the main factor of evaluations on the healthcare service delivery, thus customer-oriented behaviour is crucial in the service industry (Hartline and Ferrell, 1996).

Customer-oriented behaviours required the service provider to actively listen to the customers during interactions and propose the necessary solutions in order to meet customers' needs and satisfaction (Jin, Tom and Alex, 2017). Lanjananda and Patterson (2009) and Ong and Johari (2013) stressed that customer-oriented behaviour is also critical in the healthcare sector in order to provide higher quality of nursing care. Nurses represent the majority of positions in any hospital (Atefi, 2014) and the duration of interaction between nurses and patients is known to be the longest than any other workforce in the hospital (Fleischer et al., 2009). Hence, nursing services contribute more significantly than any other service to overall perceptions of healthcare service quality. Nurses play key roles in providing care for patients, helping organizations to meet their goals and overcoming challenges through quality performance (Amadi, 2015; Broom and Tilbury, 2007). The demand for nurses is high in developed and developing countries, Malaysia is not excepted (Barnett, Namasivayam and Narudin, 2010). The increasing in ageing populations, customer engagement, rapid development of medical technologies contributed to the increasing demand of nursing personnel (Simoens et al., 2005) as well as population growth and the associated burden of diseases (Barnett, Namasivayam and Narudin, 2010). Consequently, a drastic growth in the number of schools and nursing colleges, nursing students and consecutive increment in the proportion of new graduates within the workforce can be observed (Barnett, Namasivayam and Narudin, 2010). However, the new generation of nursing graduates were being criticized for their dissatisfactory attitudes towards patients and deterioration in the standard service delivery performance which has been identified as the contributing factors to the increasing number of complaints and criticisms on nurses received by Ministry of Health Malaysia (Barnett, Namasivayam and Narudin, 2010; Ministry of Health, 2019). Researchers argued that such a rapid expansion of schools and nursing colleges, nursing students and increasing new graduates proportion within the workforce are alarming since the workforce long-term sustainability and quality of care are uncertain, unless impactful approach is taken to resolve the issues (Barnett, Namasivayam and Narudin, 2010).

Customer-oriented behaviour is an essential approach should be taken by the organization and individual level in order to attain excellent quality service (Peccei and Rosenthal, 2001) as it encourage more efficient service delivery, improves customer satisfaction and facilitates the organization to meet customers' changing needs (Bettencourt et al., 2001; Tang and Tang, 2012; Teng and Barrows, 2009). As the behaviour of nurse moves towards a sustainable advantage of service quality, Ong and Johari (2013) suggested that the new generation of nursing workforce should adapt their customer-oriented behaviour according to the customized needs of the patient in order to provide them with better service or treatment. Without understanding customer-oriented behaviour, the entrusted responsibilities of nursing personnel may not be able to be delivered effectively and tend to miscarry the main goal of prioritizing the patients' needs (Lim, 2016). Consequently, proper care and attention 
may not be delivered to the patients and resulting in patients feeling neglected and unsatisfied.

Meanwhile, personality traits have been established to predict and determine human behaviour at work (Barrick and Mount, 1991; Barrick and Mount, 2005; Brown et al., 2002). It is crucial to understand on how personality traits can influence or predict customer-oriented behaviour. Big five personality model has been preferred in psychology and management researches (DeShong et al., 2015; Thompson and Prendergast, 2015). It has been established as the best description of personality structures across cultures (Digman, 1990; Harari et al., 2014; Wiggins and Trapnell, 1997) and proven as a robust indicator to determine individual's personality (Goldberg, 1981; Haq et al, 2010; Poropat, 2009; Wortman et al., 2012). This study adopts all five dimensions of big five personality model to holistically examine the nursing students' personality traits as it can serves as the predictor towards customer-oriented behaviour.

In addition, researches showed emotional intelligence relates with behaviours (Jordan and Troth, 2004; Ramachandran et al., 2011; Robbins et al., 2010; Shih and Susanto, 2010). Kong et al. (2016) indicated that emotional intelligence was positively associated with clinical ability, this is because nursing students with high emotional intelligence may be able to understand the patient's perspective better and they are also likely to experience empathy. Hence, emotional intelligence may have significant influence towards nursing students' customer-oriented behaviour. Therefore, the present study aims;

- To examine the effects of the big five personality traits on customer-oriented behaviour

- To examine the effects of big five personality traits on emotional intelligence

- To examine the effects of emotional intelligence on customer-oriented behaviour

- To examine the mediating effects of emotional intelligence on the relationship between big five personality traits and customer-oriented behaviour

\section{Literature Review}

\section{Customer-Oriented Behaviour}

Customer-oriented behaviour is conceptualized from customer orientation where it is a concept and a belief that often gives priority to the interest of the customer. This concept has been addressed by Jaworski and Kohli (1993) explaining that it is a collection of organizational behaviours employed to gather and use customer information in order to gain customer satisfaction. Many researchers stressed the critical importance of frontline employees customer-oriented behaviour regarding quality service delivery and customers' satisfaction from diverse global perspectives (Narver and Slater, 1990; Brown et al., 2002; Chen and Chen, 2010). Customer-oriented behaviour refers to specific behaviours exhibited by service personnel during service delivery which behaviours that results to satisfied customers (Farrell, Souchan and Furden., 2001; Winsted, 2000a, b). Ong and Johari (2013) described customeroriented behaviour as a particular individual behaviour that is necessary to satisfy the customer's needs by providing the right solutions.

In the healthcare context, it is explained that the term customer-oriented behaviour applies to the behaviour of service providers and the ability of care providers to offer in order to reflect the reality of patients (Daniel and Darby, 1997). Chien, Chou and Hung (2008) identified customer-oriented behaviour in the healthcare context as the degree to which nurses understand patient needs and wishes. On the same note, Daniel and Darby (1997) 
made it clear that the term customer-oriented behaviour refers to the behaviour of caregivers in the service and the ability to adjust their service to reflect the reality of the patient. Darby and Daniel (1999) indicated that the interface between nurses and patients involves elements of nurse-patient interaction in the service delivery process. Therefore, customer-oriented behaviour is an essential interface element for nurses to meet the increasing expectations from patients.

\section{Personality Traits and Customer-Oriented Behaviour}

The traits theory notes that traits guide an individual's behaviour in which that behaviour is compatible with that person's personality traits (Allport, 1961). This theory underpins three key assumptions: (1) everyone has traits; (2) the goal of life is to discover one's traits; and (3) the goal of personality assessment is to evaluate traits (Allport, 1961; Hogan and Sherman, 2020). Traits tend to be divided between circumstances and hence incorporate for permanent, robust and general characteristics of the behaviour of individuals (Allport, 1961; Hogan and Sherman, 2020). Personality traits are considered to be a consistent set of characteristics that are responsible for the personality of a person and thus influence behaviour (Kinicki, 2008). The Five-Factor Model or also known as Big Five Personality Traits consisting of openness to experience, conscientiousness, extraversion, agreeableness and neuroticism has been described as a trait descriptive characteristic (Saucier, 1997). It implicitly adopts the basic tenets of trait theory (McCrae and John, 1992). The big five personality traits are the most commonly accepted model for the study of individual personality (Goldberg, 1990; McCrae and Costa, 1987; McCrae and John, 1992). In fact, many psychologists established the big five personality traits as the best personality traits description due to its authenticity and effective model for assessing the personality of an individual across various cultures (Digman, 1990; Harari et al., 2014; Wiggins and Trapnell, 1997). It has been proven as a robust predictor for the determination of individual personality (Goldberg, 1981; Haq et al., 2010; Poropat, 2009; Wortman et al., 2012). Researchers have shown that the behaviour of service personnel is influenced by their personality traits (Liao and Chuang, 2004; Schneider and Smith, 2004) and have significant relationship with customer-oriented behaviour (Johari and Ong, 2013).

The factor of openness to experience refers to intellectually curious and creative individuals (Costa and McCrae, 1992). Individuals with high openness factor are typically associated with intellectual ability and supported by several studies through significant correlation between intelligent and openness to experience. They are also anticipated to be more insightful, intellectual, analytical and logical (Judge and Zapata, 2015; McCrae and Sutin, 2009). Open individuals able to accept and to understand uncommon occurrence (Watanabe et al., 2011). In addition, individuals with a high degree of openness to experience have a multiplicity of interests, versatility of thinking and responsive to new ideas. They are likely to take an active part in their work as they view it as a medium for their curiosity, genuine interests and new insights (Bozionelos, 2004). They always think creatively and tend to figure out alternative ways to solve an issue, particularly during a stressful situations (Mount, Barrick and Stewart, 1998). Wanberg and Kammeyer-Mueller (2000) defined openness as a predictor of proactivity in the process of socialization. Johari and Ong (2013) in their study reported that openness to experience is capable to indicate the customer-oriented behaviour of nurses in the Malaysia healthcare tourism hospitals. Hence, openness to experience is an important element to predict customer-oriented behaviour among nursing students. Openness to experience is likely to generate customer-oriented behaviour. Therefore, it is proposed that: 
Proposition 1(a): Openness to experience trait has a significant positive relationship with customer-oriented behaviour.

Conscientiousness has been correlated with many organizational and individual outcomes. For example, Liao and Chuang (2004) reported that conscientious service personnel appear to perform better than those low in conscientiousness. DeShong et al. (2015) stressed that conscientiousness is the only indicator of counterproductive workplace behaviour. Ellershaw et al. (2015) reported that conscientious nurses had substantially higher performance as compared to low conscientious nurses. According to Judge and Ilies (2002), the conscientious employees' higher performance has been associated to their decisive and orderly characteristics, which offer them an advantage in different job roles. Johari and Ong (2013) in their study emphasized that conscientiousness trait able to predict nurses' customer-oriented behaviour in the Malaysia healthcare tourism hospitals. Conscientious individuals have the ability to depersonalize stressful circumstances and always prioritize work performance. Therefore, conscientiousness is likely to generate customer-oriented behaviour among nursing students. On this basis, it is proposed that:

Proposition 1(b): Conscientiousness trait has a significant positive relationship with customer-oriented behaviour.

The extraversion trait is correlated with the tendency of individuals to be talkative, active, gregarious, assertive and sociable (Salgado, 1997). Throughout the literature, many positive effects have been linked with extraversion. According to Judge et al. (1999), extraversion has a beneficial impact on the progress of an extrinsic career which highlighted income and professional status as the main motivation. The extraverts are more likely to excel in their careers and prone to be in higher jobs, thereby posses higher earnings than individuals with low extraversion. Extraverts who typically seek social attention and excitement tend to spend more time with others, maintain more social contact, socializing and spend most of their time engaging in social activities, while introverts are quite the opposite (Bono and Judge, 2004; Bruck and Allen, 2003; Kandler, 2012; Smillie et al., 2015; Wanberg et al., 2000). Moreover, extraverts tend to be happier both in general and in short periods of time. According to Barrick and Mount (1991), extraverts are reported to exhibit higher results in jobs that require higher degree of interpersonal skills such as sale representatives and managerial positions. In their research, Barrick and Mount (1993) noted that there is a positive relationship between extraversion and job involving high-social interaction. Since nursing profession requires high degree of interpersonal skills and social interaction, hence, extraversion trait is prone towards nursing students' customer-oriented behaviour. Therefore, it is proposed that:

Proposition 1(c): Extraversion trait has a significant positive relationship with customeroriented behaviour.

Individuals high in agreeableness are generous, trusting, honest, sympathetic to others, soft hearted, courteous, altruistic, good-natured, modest, helpful and tolerant (Bruck and Allen, 2003; Driskell et al., 2006). Individuals with high agreeableness are indicated by their willingness to trust others and to create and sustain relationships (Bono and Judge, 2004). In addition, researchers believed that agreeableness is a social trait (Judge and Bono, 2000). In fact, the degree of agreeableness in individual is one of the key determinants of how people 
relate to each other and how much people value interpersonal relationship (Myers and Myers, 2010). Agreeable individuals are best in establishing and sustaining relationships both within and outside of the work environment (Bono et al., 2002). They appear to be happier as they experience less conflict due to the high value they offer to their relationship with others (Bono et al., 2002). Barrick, Stewart and Piotrowski (2002) noted that agreeable employees prone to be more successful in their jobs since they prioritize teamwork and customer service as the key performance indicators. This is due to the fact that agreeable individuals are generally friendly, empathetic and altruistic in delivering their job and respectful in handling their peers (Salgado, 1997). Based on the above mentioned, it is proposed that:

Proposition 1(d): Agreeableness trait has a significant positive relationship with customeroriented behaviour.

Neuroticism is associated with susceptibility of individuals to negative emotions. Individuals with higher neuroticism are said to be low emotional stability which susceptible to feel guilt, paranoid, depression, anxiety, anger, fear, embarrassment, disgust, selfconsciousness and mood swings (Alessandri and Vecchione, 2012; Hui-Hua and Schutte, 2015). In addition, they are prone to lose control and being reactive (Alessandri and Vecchione, 2012; Hui-Hua and Schutte, 2015). Neurotic people are more likely to experience anxiety which may affect their cognitive and behavioural actions (McCrae and John, 1992). High neuroticism individuals are likely to focus on negative encounters and experience a broad range of psychiatric disorders. Neurotic individuals are insecure, stress and indecisive (Ehrhant, 2006). Provided the nature of work in the hospital setting, emotions instability will certainly result in poor service to the patients. Hence, individuals which high in neuroticism are less likely to display customer-oriented behaviour (Ong and Johari, 2014). Thus, it is proposed that:

Proposition 1(e): Neuroticism trait has a significant negative relationship with customeroriented behaviour.

\section{Personality Traits and Emotional Intelligence}

Interest in the potential value of emotional intelligence development in order to build and to retain nursing competence has getting attention since the last decade. Emotional intelligence is defined as an individual's ability to understand his or her own and others' emotions in a timely manner and utilizing those emotions wisely to produce desirable results (Kunnanatt, 2004). Emotional intelligence theories can be broadly divided into two models named as the mental ability model or ability model (Mayer and Salovey, 1997) and mixed model (Goleman, 1999) that are widely studied in the past. The ability-based model is regarded as absolute ability emotional intelligence model that has been put forward by Mayer and Salovey (1997), with four branches of emotional intelligence namely as self-emotions appraisal, other's emotional appraisal, regulation of emotions and utilization of emotions. The mixed model of emotional intelligence proposed by Goleman (1999) has been conceptualized into a construct encompassing five competencies namely as self-awareness, self-regulation, self-motivation, empathy and social skills (Pettijohn, Rozell and Newman, 2010). This model measures the ability, social competencies and character (Zeidner et al., 2002). Researchers claimed that big 
five personality traits were significantly related to emotional intelligence (Mahasneh, 2013; Nawi et al., 2015; Saklofske et al., 2003; Vakola et al., 2004; Zee et al., 2002).

Openness to experience is known as intellectual trait. Individuals high in openness to experience are considered to be original, cultured and able to take risks (Costa and McCrae, 1992). Zee et al. (2002) mentioned in their study that quasi-ability factor makes this trait somewhat similar to intelligence. In addition, openness to experience is utilized to define the intelligence of human beings features like creative-minded, bright and smart (Ashton et al., 2000). Thus, it can be expected that individuals high in openness to experience are intelligence to appreciate and managing their emotions. Researchers found that openness to experience trait has positive correlation with emotional intelligence (Ciarrochi et al., 2000; Dawda and Hart, 2000; Kappagoda, 2013; Matthews et al., 2006; Nawi et al., 2012; Petrides and Furnham, 2001; Schutte et al., 1998; Shulman and Hemenover, 2006). Saklofske et al. (2003) noted a positive significant correlation between openness to experience and emotional intelligence. Similarly, Mahasneh (2013) and Nawi et al. (2015) empirically proven that openness to experience has a significant effect on the emotional intelligence construct. Thus, it is proposed that:

Proposition 2(a): Openness to experience has a significant positive relationship with emotional intelligence.

The conscientiousness trait of personality refers to the personality attributes like vigilance, responsibility, discipline, carefulness, reliability, dependability and persistence (Barrick and Mount, 1991), high degree of thoughtfulness, being organized and mindful of information, with good impulse control and goal-oriented behaviour (Yusoff et al., 2013). Some researchers reported that there is no significant relationship between conscientiousness trait and emotional intelligence (Kappagoda, 2013; Shulman and Hemenover, 2006; Warwick and Nettelbeck, 2004). On the other hand, numerous of researchers emphasized on the significant relationship between conscientiousness and emotional intelligence (Beshart, 2010; Christoper et al., 2011; Douglas et al., 2004; Hudani et al., 2012; Matthews et al., 2006; McCrae, 2000; Nawi et al., 2012; Sala, 2002). The study of Zee et al. (2002) concluded a positive significant relationship between conscientiousness trait and emotional intelligence. In the study of Austin et al (2008), they have proven through their structural equation modelling that conscientiousness positively predicts emotional intelligence. In fact, Nawi et al. (2015) declared that conscientiousness trait as the strongest predictor of emotional intelligence as compared to other personality traits. Therefore, it is proposed that:

Proposition 2(b): Conscientiousness has a significant positive relationship with emotional intelligence.

The extraversion trait of personality refers to attributes like being assertive, active, talkative, sociable and full of positive emotions (Costa and McCrae, 1992). These individuals are considered to be unreserved and more informal in developing contacts with others. They enjoy frequent interactions and strive to get along with other (Costa and McCrae, 1992). The aforementioned attributes are related to the concept of interpersonal intelligence defined by Gardner (1983). Thus, it is expected that extraversion trait has a significant relationship with emotional intelligence. Moreover, past studies discovered positive relationship between extraversion and emotional intelligence (Austin et al., 2008; Bagby et al., 1994; Brackett and 
Mayer, 2003; Davies et al., 1998; Matthews et al., 2006; McCrae, 2000; Newness et al., 2012; Saklofske, 2003; Sala, 2002; Vakola et al., 2004; Warwick and Nettelbeck, 2004). In addition, Pettijohn, Rozell and Newman (2010) reported that emotional intelligence positively correlated with customer orientation levels. Based on the past studies that supported the significant relationship between extraversion and emotional intelligence, extraversion trait predicted to exhibit customer-oriented behaviour and emotional intelligence correlated to customer orientation level, therefore it is proposed that:

Proposition 2(c): Extraversion has a significant positive relationship with emotional intelligence.

The agreeableness trait refers to the personality attributes as warmth, cooperation, sensitivity to others' feelings, trust, sympathy and altruism (Costa and McCrae, 1992). Individuals high in agreeableness are indicated to have better relationships and effective communication with others (Shaffer, 2004). Zee et al. (2004) hypothesized in their study that agreeableness trait has significant relationship with behavioural and cognitive process of controlling the emotions of others. There are numerous of past studies reported positive correlation between agreeableness and emotional intelligence even though the correlation results are not as strong as the correlation score of extraversion and conscientiousness with emotional intelligence (Dawda and Hart, 2000; Matthews et al., 2006; Newness et al., 2012; Petrides and Furnham, 2001). Austin et al. (2008) and Nawi et al. (2015) in their studies also have empirically proven that agreeableness trait positively and significantly predicts emotional intelligence. On the basis of the findings aforementioned and establish relationship between emotional intelligence and customer orientation levels (Pettijohn, Rozell and Newman, 2010), it is proposed that:

Proposition 2(d): Agreeableness has a significant positive relationship with emotional intelligence.

Neuroticism trait is associated with the attributes of being depressed, anxious, worried, vulnerable, insecure and can be easily provoked (Costa and McCrae, 1992). In contrast, individuals with high emotional stability are more relaxed, secure, confident, well-adjusted, and able to cope with stressful circumstances (Bruck and Allen, 2003; Kandler, 2012). Individuals high in neuroticism trait are less likely to display customer-oriented behaviour (Ong and Johari, 2014). In addition, numerous studies have established positive correlation between emotional stability and emotional intelligence (Austin et al., 2008; Bagby et al., 1994; Davies et al., 1998; Dawda and Hart, 2000; Matthews et al., 2006; Newness et al., 2012; Petrides and Furnham, 2001; Roger and Najarian, 1989; Warwick and Nettelbeck, 2004). Saklofske et al. (2003) and Vakola et al. (2004) discovered an overall negative correlation between neuroticism and emotional intelligence score. Since researchers have established relationship between emotional intelligence and customer orientation levels (Pettijohn, Rozell and Newman, 2010) together with the supported aforementioned findings, it is proposed that:

Proposition 2(e): Neuroticism has a significant negative relationship with emotional intelligence. 


\subsection{Emotional Intelligence and Customer-Oriented Behaviour}

Emotional intelligence is a crucial concept for nurses to understand the patients' perspectives and demands (McQueen, 2004). Extensive researches have empirically supported that emotional intelligence is related to behaviour. Previous studies have affirmed the predictive power of emotional intelligence on behaviour such as conflict resolution (Jordan and Troth, 2004; Shih and Susanto, 2010). Jordan and Troth (2004) highlighted that individuals with emotional intelligence are able to resolve interpersonal conflicts. Consistently, emotional intelligence is commonly seen as the ability to understand and to manage emotional experiences and responses in self and others and then combining these to improve thought and consequent behaviours (Serrat, 2017). Each of the five competencies of emotional intelligence proposed by Goleman (1999) has an impact on how individuals perceives and responds to all kind of events (Pettijohn, Rozell and Newman, 2010). For instance, there is a strong connection between self-regulation and behaviour choice since it involves self-control, adaptability and self-monitoring within a specific conditions. Moreover, empathy and motivation are likely to guide the way individuals perceive circumstances and indirectly influence the choice of responsive behaviour (Pettijohn, Rozell and Newman, 2010). Goleman's competencies set has embarked the concern in adopting and implementing the emotionally intelligent policies within organizations (Pettijohn, Rozell and Newman, 2010). Thus, the concept discussed by Goleman (2001) seems to be closely linked to the behaviours and predispositions of a customer-oriented behaviour especially for nursing students. Therefore, it is proposed that:

Proposition 3: Emotional intelligence has a significant positive relationship with customeroriented behaviour.

\subsection{Mediating Effects of Emotional Intelligence}

Nursing usually be seen as an intense profession which takes place in a demanding working atmosphere (Kaya, Senyuva and Bodur, 2018). This profession demanded nurses to have emotional intelligence skill in order to recognize patient's needs, to make fast and precise decisions, to interpret patients' complex information from various angles (Altuntas et al., 2010; Fidanci et al., 2012; Heffernan et al., 2010; Ip et al., 2000; Kawashima and Petrini, 2004; Kaya and Yalniz, 2012; Kucukguclu and Kanbay, 2011; Mangena and Chabeli, 2005). Owing to that fact, it is important to acquire these skills during undergraduate education (Kaya, Senyuva and Bodur, 2018). However, the number of empirical studies conducted in the subject of emotional intelligence on nursing students is limited. In fact, study on the mediating effect of emotional intelligence on customer-oriented behaviour among Malaysian nursing students has not yet been done. Therefore, a study of mediating effect on the relationship between big five personality traits and customer-oriented behaviour among Malaysia nursing students is indispensable to fill up the gap.

Emotional intelligence construct as a mediator variable serves to define the nature of the relationship between the independent and dependent variables. Significant numbers of studies have tested the mediating effect of emotional intelligence. Kang and Bae (2015) showed that emotional intelligence mediates the relationship between emotional labour and psychological well-being. The study also suggested that hospitals should develop education and training programs to enhance emotional intelligence skills among nurses and promote clinical nurses' psychological well-being. In addition, De Haro, Castejon and Gilar (2018) confirmed the mediator effect of emotional intelligence on the relationship between 
personality traits and earnings. Emotional intelligence also confirmed to fully mediates the effect of occupational stress on job performance (Ismail et al., 2009). According to Schutte and Malouff (2011), emotional intelligence did significantly mediate between mindfulness and subjective well-being which comprised of higher positive affect, lower negative affect and greater life satisfaction. Individuals with emotional intelligence manage their emotions in order to excel at work and in life and practice empathic prosocial behaviours (Miao, Humphrey and Qian, 2017). Research conducted by Saklofske et al. (2007) indicated that emotional intelligence is significantly mediated the relationship between personality and exercise behaviour. This view suggests that emotional intelligence would be an important variable predicting the relationship between big five personality traits and customer-oriented behaviour. This gives an implication that studying emotional intelligence as a mediator is valid and thus, guaranteed that the present study is likely to achieve its objectives by viewing emotional intelligence as a mediator between big five personality traits and customeroriented behaviour. Therefore, it is proposed that:

Proposition 4: Emotional intelligence significantly mediates the relationship between big five personality traits and customer-oriented behaviour.

\section{Theoretical Framework}

There are limited empirical studies and scholars focus on the topic of customer-oriented behaviour among nursing students. As for this study, trait theory and emotional intelligence theory are integrated in designing the research framework. The framework of this study presents its newness by investigating these variables together simultaneously which never been tested previously especially in the context of Malaysia public healthcare as shown in Figure 1 . The relationship between big five personality traits and customer-oriented behaviour and the mediating role of emotional intelligence on the relationship between big five personality traits and customer-oriented behaviour among Malaysian nursing students will be tested.

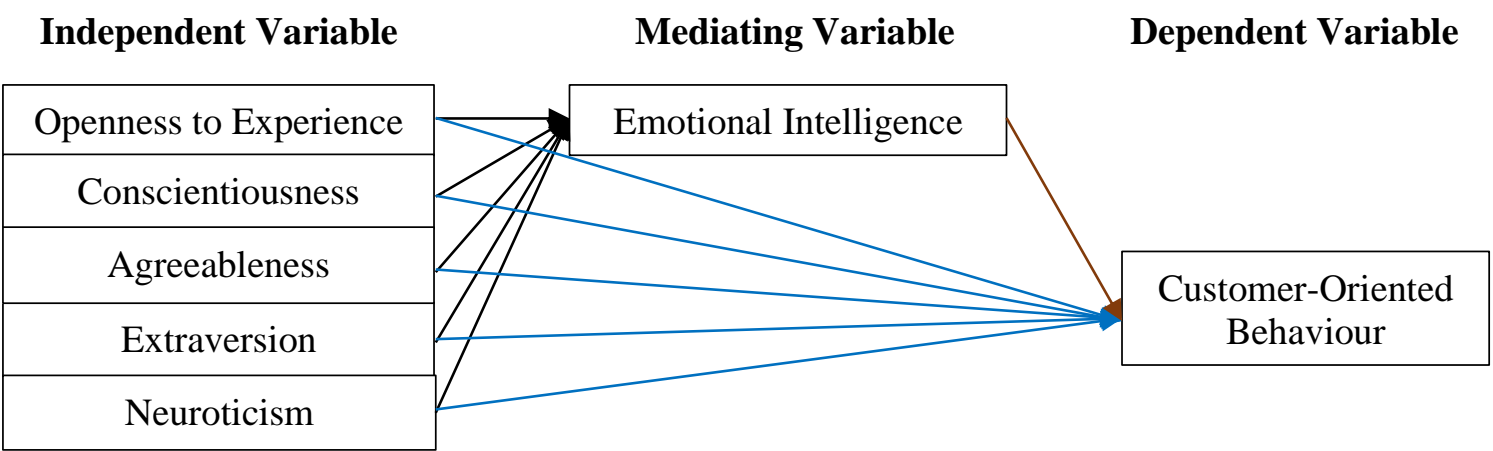

Figure 1: Proposed Theoretical Framework

\section{Research Implications}

This study aims to show a better understanding of nursing students' customer-oriented behaviour and the mediating effects of emotional intelligence on the relationship between big five personality traits and customer-oriented behaviour. It further contributes to the extant research of customer-oriented behaviour in the healthcare context by introducing emotional intelligence as a mediator in the research model. Although in the past, few 
researchers studied the mediation effect of emotional intelligence between psychological processes and customer-oriented behaviour, however, the role of emotional intelligence is not yet been discussed between the relationships of personality traits and customer-oriented behaviour. The reason of this undiscovered mediating role of emotional intelligence might be the lack of consensus among researchers about conceptualization of emotional intelligence construct. As for this study, trait theory and emotional intelligence theory are integrated in designing the research framework. Furthermore, from the review of literature, empirical evidences on the relationship between personality and emotional intelligence (Mahasneh, 2013; Nawi et al., 2015); and emotional intelligence and customer-oriented behaviour have been found. Hence, based on the theoretical and empirical underpinnings, the ability of emotional intelligence construct to serve as mediator in the relationship between big five personality traits and customer-oriented behaviour is going to be investigated in this study which would be a significant contribution in the current empirical body of literature on emotional intelligence. The findings of this study will serve as a new contribution and extend to the existing knowledge on which dimensions of personality traits significantly contribute towards customer-oriented behaviour among Malaysian nursing students and the mediating effects of emotional intelligence.

In terms of practical implications, this study is highly important for Malaysian public healthcare particularly nursing students. This study suggests the guideline regarding which dimensions of personality can be considered high in emotional intelligence that will ultimately lead to greater customer-oriented behaviour. This can be a beneficial guideline for Student Recruitment Department of public nursing colleges to find and filter the best candidates which having the best personality traits of becoming nurses to enrol in the nursing courses which may lead to good achievement with high level of customer-oriented behaviour. Consequently, it is also contribute towards the objective of Ministry of Health to become the best healthcare provider globally and achieve the required nurse to patient ratio 1:200 as set by the World Health Organization.

\section{Conclusion}

This study builds upon the extant literature on customer-oriented behaviour, emotional intelligence and big five personality traits which leads to the proposed theoretical framework. Customer-oriented behaviour is a crucial antecedent in healthcare sector and as an important approach in addressing the criticisms and complaints received by the nurses. Owing to the fact that the quality of care delivered by nurses are questionable and the long-term sustainability of the nursing workforce is uncertain, therefore, better understanding on customer-oriented behaviour among nursing students is very crucial to resolve this matter. Through better understanding of the customer-oriented behaviour among nursing students, healthcare service performance could be improved and consequently enhance customer satisfaction and organizations' performance index.

This study is highly important from theoretical and practical aspects. It offers a new insight on the effects of big five personality traits on customer-oriented behaviour and emotional intelligence. Besides, this study will also establish the mediating effect of emotional intelligence on the relationships between big five personality traits and customer-oriented behaviour among Malaysian nursing students. The population considered in this study is also very important from a theoretical aspect because nursing students are the successors of the main representations of healthcare services since nurses constitute the majority positions in any hospitals. In addition, this study also adds to the literature of customer-oriented 
behaviour especially in the area of healthcare services which may guide future empirical research in this context. In terms of practical contribution, the findings of this study are expected to provide relevant information about which dimensions of personality traits are significant predictors for customer-oriented behaviour. Recruitment managers can use this information as a basis to select the right candidates for customer-oriented personnel. In addition, measuring and identifying the existing state of customer-oriented behaviour can essentially aid managers in designing training programs to improve the level of service behaviour among various levels of personnel in the healthcare sector.

\section{Acknowledgments}

I am grateful for the assistance, continuous guidance and support given by my supervisor, Dr. Ong Choon Hee throughout this study. This study is funded by Zamalah Scholarship provided by Universiti Teknologi Malaysia (UTM).

\section{References}

Alessandri, G., and Vecchione, M. (2012). The higher-order factors of the Big Five as predictors of job performance. Personality and Individual Differences, 53(6), 779-784.

Allport, G. W. (1961). Pattern and Growth in Personality. New York Holt Reinehart Winston.

Altuntas, S., Akyil, R., and Burkay, O. F. (2010). The Level of Emotional Intelligence in Male Nursing Students. [Paper presentation]. National Nursing Students Conference, Fethiye.

Amadi, E. (2015). Healthcare Leaders' Perceptions about the Nursing Shortage: A Qualitative Collective Case Study [Degree of Health Administration Dissertation]. University of Phoenix.

Atefi, N. (2014). Comparing Job Satisfaction Among Registered Nurses in an Iranian Hospital and a Malaysian Hospital [Doctor of Philosophy Thesis]. University of Malaya, Kuala Lumpur.

Austin, E. J., Dore, T. C. P., and O'Donovan, K. M. (2008). Associations of personality and emotional intelligence with display rule perceptions and emotional labor. Personality and Individual Differences, 44, 679-688. doi:10.1016/j.paid.2007.10.001

Bagby, R. M., Parker, J. D., and Taylor, G. J. (1994). The 20-item Toronto Alexithymia Scale: I. Item selection and cross validation of the factor structure. Journal of Psychosomatic Research, 38, 23-32.

Barnett, T., Namasivayam, P., and Narudin, D. A. A. (2010). A critical review of the nursing shortage in Malaysia. International Nursing Review, 57, 32-39.

Barrick, M. R., and Mount, M. K. (1991). The Big Five personality dimensions and job performance: A meta-analysis. Personnel Psychology, 44, 1-26.

Barrick, M. R., and Mount, M. K. (1993). Autonomy as a moderator of the relationship between the Big Five personality dimensions and job performance. Journal of Applied Psychology, 78, 111-118.

Barrick, M. R., and Mount, M. K. (2005). Yes, personality matters: Moving on to more important matters. Social Performance, 18(4), 359-372. In Bartlett, Kotrlik and Higgins, 2001.

Barrick, M., Stewart, G., and Piotrowski, M. (2002). Personality and job performance: Test of the mediating effects of motivation among sales representatives. Journal of Applied Psychology, 87, 43-51. 
Beshart, M. A. (2010). The relationship between emotional intelligence and self-efficacy and academic success. Education Renovation Journal, 2 (10), 1-10.

Bettencourt, L. A., Gwinner, K. P., and Meuter, M. L. (2001). A comparison of attitude, personality, and knowledge predictors of service-oriented organizational citizenship behaviours. Journal of Applied Psychology, 86, $29-41$.

Bono, J. E., Boles, T. L., Judge, T. A., and Lauver, K. J. (2002). The role of personality in task and relationship conflict. Journal of Personality, 70, 311-344.

Bono, J. E., and Judge, T. A. (2004). Personality and transformational and transactional leadership: A meta-analysis. Journal of Applied Psychology, 89 (5), 901-910.

Bozionelos, N. (2004). The big five of personality and work involvement. Journal of Managerial Psychology, 19(1), 69-81. https://doi.org/10.1108/02683940410520664

Brackett, M. A., and Mayer, J. D. (2003). Convergent, discriminant, and incremental validity of competing measures of emotional intelligence. Personality and Social Psychology Bulletin, 29, 1147-1158.

Broom, C., and Tilbury, M. S. (2007). Magnet Status: A journey, Not A Destination. Journal of Nursing Care Quality, 22(2), 113-118.

Brown, T. J., Mowen, J. C., Donavan, D. T., and Licata, J. W. (2002). The customer orientation of service workers: Personality trait effects on self-and supervisor performance ratings. Journal of Marketing Research, 39(1), 110-119.

Bruck, C. S. and Allen, T. D. (2003). The relationship between big five personality traits, negative affectivity, type A behavior and work-family conflict. Journal of Vocational Behavior, 63, 457-472.

Bruno, A., Dell'Aversana, G., and Zunino, A. (2017). Customer Orientation and Leadership in the Health Service Sector: The Role of Workplace Social Support. Frontiers in Psychology, 8: 1920.

Chen, M. L., and Chen, K. J. (2010). The relations of organizational characteristics, customeroriented behaviour and service quality. African Journal of Business Management, 4(10), 2059-2074.

Chien, C. C., Chou, H. K., and Hung, S. T. (2008). A conceptual model of nurses' goal orientation, service behaviour and service performance. Nursing Economics, 26 (6), 374-383.

Christopher, H., Kamlesh, S. and Brett, L., (2011). The Happy Personality in India: The Role of Emotional Intelligence. Journal of Happiness Study, 12, 807-817.

Ciarrochi, J., Chan, A., and Caputi, P. (2000). A Critical Evaluation of the Emotional Intelligence Construct. Personality and Individual Differences 28: 539-61.

Costa, P. T., and McCrea, R. R. (1992). Four ways five factors are basic. Personality and Individual Differences, 13(6), 653-665.

Daniel, K., and Darby, D. N. (1997). A dual perspective of customer motivation: a modification, extension and application of the SOCO scale. International Journal of Service Industry Management, 8 (2), 131-47.

Darby, D. N. and Daniel, K. (1999). Factors that influence nurses' customer orientation. Journal of Nursing Management, 7, 271-80.

Davies, M., Stankov, L., and Roberts, R. D. (1998). Emotional intelligence: In search of an elusive construct. Journal of Personality and Social Psychology, 75, 989-1015.

Dawda, D., and Hart, S. D. (2000). Assessing emotional intelligence: Reliability and validity of the Bar-On Emotional Quotient Inventory (EQ-i) in university students. Personality and Individual Differences, 28, 797-812. 
De Haro, J. M., Castejon, J. L., and Gilar, R. (2018). Personality and salary at early career: The mediating effect of emotional intelligence. The International Journal of Human Resource Management, 31(14), 1844-1862.

DeShong, H. L., Grant, D. M., and Mullins-Sweatt, S. N. (2015). Comparing models of counterproductive workplace behaviors: The Five-Factor Model and the Dark Triad. Personality and Individual Differences, 74, 55-60.

Digman, J. M. (1990). Personality structure: Emergence of the five-factor model. Annual Review of Psychology, 417-440.

Douglas, C., Frink, D. D., and Ferris, G. R. (2004). Emotional intelligence as a moderator of the relationship between conscientiousness and performance. Journal of Leadership and Organizational Studies, 10 (3), 2-13.

Driskell, J. E., Goodwin, G. F., Salas, E. and O'Shea, P. G. (2006). What makes a good team player? Personality and team effectiveness. Group Dynamics: Theory, Research, and Practice, 249-271.

Ehrhart, K. H. (2006). Job characteristic beliefs and personality as antecedents of subjective person-job fit. Journal of Business and Psychology, 21, 193-226.

Ellershaw, J., Fullarton, C., Rodwell, J., and Mcwilliams, J. (2015). Conscientiousness, openness to experience and extraversion as predictors of nursing work performance: a facetlevel analysis. Journal of Nursing Management, 1-9.

Farrell, M., Souchon, A. L., and Furden, G. L. (2001). Service encounter conceptualisation: employees' service behaviors and customers' service quality perceptions. Journal of Marketing Management, 17 (5-6), 577-593.

Fidanci, B. E., Cinar, F. I., Yildiz, D., Akar, F., Turk, A., Tuncer, S., Bala, A., and Kökce, B. D. (2012). Evaluation of the critical thinking skills and factors affecting these skills in students of high school nursing. Gulhane Med. J. 54, 35-39.

Fleischer, S., Berg, A., Zimmermann, M., Wuste, K. and Behrens, J. (2009). Nurse-patient interaction and communication: A systematic literature review. Journal of Public Health, 17, 339-353.

Gardner, H. (1983). Frames of mind. New York: Basic Books.

Goldberg, L. R. (1981). Language and individual differences: The search for universals in personality lexicons. In L. Wheeler (Ed.), Review of personality and social psychology, 2, 141-165. Beverly Hills, CA: Sage.

Goldberg, L. R. (1990). An Alternative Description of Personality: The Big-Five Factor Structure. Journal of Personality and Social Psychology, 1216-1229.

Goleman, D. (2001). An El-based theory of performance, in Cherniss, C. and Goleman, D. (Eds), The Emotionally Intelligent Workplace: How to Select for, Measure, and Improve Emotional Intelligence in Individuals, Groups, and Organizations, Jossey-Bass, San Francisco, CA, 27-44.

Haq, I. U., Ramay, M. I., Rehman, M. A. and Jam, F.A. (2010). Big Five Personality and Perceived Customer Relationship Management. Journal of Business and Retail Management Research. 6(1), 37-45.

Harari, M. B., Jain, N. K., and Joseph, T. (2014). The Five-Factor Model of Personality and Knowledge Transfer in the United Arab Emirates. International Journal of Selection and Assessment, 22(4), 399-410.

Hartline, M. D., and Ferrell, O. C. (1996). The management of customer-contactmservice employees: An empirical investigation. Journal of Marketing, 60, 52-70. 
Heffernan, M., Griffin, Q. M. T., McNulty, S. R., and Fitzpatrick, J. J. (2010). Self-compassion and emotional intelligence in nurses. International Journal of Nursing Practice, 16, 366-373. http://dx.doi. org/10.1111/j.1440-172×.2010.01853.x

Hogan, R., and Sherman, R. A. (2020). Personality theory and the nature of human nature. Personality and Individual Differences, 152, 109561. https://doi.org/10.1016/j.paid.2019.109561

Hudani, M. N., Redzuan, M., and Hamsan, H. (2012). Inter Relationship between Emotional Intelligence and Personality Trait of Educator Leaders. International Journal of Academic Research in Business and Social Sciences, 2(5), 223-237.

Hui-Hua, Z., and Schutte, N. S. (2015). Personality, emotional intelligence and other-rated task performance. Personality and Individual Differences, 87, 298-301.

Ip, W., Lee, D., Lee, I., Chau, J., Wootton, Y., and Chang, A. (2000). Disposition towards critical thinking: a study of Chinese undergraduate nursing students. Journal of Advance Nursing, 32, 84-90. doi: 10.1046/j.1365-2648.2000.01417.x

Ismail. A., Suh-Suh, Y., Ajis, M. N., and Dollah, N. F. (2009). Relationship between occupational stress, emotional intelligence and job performance: An empirical study in Malaysia. Theoretical and Applied Economics, 16(10), 3-16.

Jaworski, B. J., and Kohli, A. K. (1993). Market orientation: Antecedents and consequences, Journal of Marketing, 57, 53-70.

Jin, H. J., Tom, J. B., and Alex, R. Z. (2017). The effect of customer-initiated justice on customeroriented behaviors. Journal of Business Research, 71, 38-46.

Johari, H., and Ong, C. H. (2013). Personality traits and customer-oriented behaviour in the health tourism hospitals in Malaysia. International Journal of Trade, Economics and Finance, 4(4), $213-216$.

Jordan, P. J., and Troth, A. C. (2004). Managing emotions during team problem solving: Emotional intelligence and conflict resolution. Human Performance, 17, 195-218.

Judge, T. A., and Bono, J. E. (2000). Five-factor model of personality and transformational leadership. Journal of Applied Psychology, 85, 751- 765.

Judge, T. A., Higgins, C., Thoresen, C. J., and Barrick, M. R. (1999). The Big Five personality traits, general mental ability, and career success across the life span. Personnel Psychology, 52, 621-652.

Judge, T. A., and Ilies, R. (2002). Relationship of personality to performance motivation: A meta-analytic review. Journal of Applied Psychology, 797-807.

Judge, T. A., and Zapata, C. P. (2015). The Person--Situation Debate Revisited: Effect of Situation Strength and Trait Activation on The Validity of The Big Five Personality Traits in Predicting Job Performance. Academy of Management Journal, 1149-1179.

Kandler, C. (2012). Nature and nurture in personality development: The case of neuroticism and extraversion. Current Directions in Psychological Science, 290-296.

Kang, S. M., and Bae, S. H. (2015). The Mediating Effect of Emotional Intelligence on the Relationship between Emotional Labor and Psychological Well-being of Clinical Nurses. Journal of Muscle and Joint Health, 22(3), 185-194.

Kappagoda, S. (2013). The relationship between emotional intelligence and five factor model of personality of English teachers in Sri Lanka. International Journal of Business, Economics and Law, 2(1), 53-59.

Kawashima, A., and Petrini, M. A. (2004). Study of critical thinking skills in nursing students and nurses in Japan. Nurse Education Today, 24, 286-292. 
Kaya, H., Senyuva, E., and Bodur, G. (2018). The relationship between critical thinking and emotional intelligence in nursing students: A longitudinal study. Nurse Education Today. 68, 26-32. doi:10.1016/j.nedt.2018.05.024

Kaya, H., and Yalniz, N. (2012). Critical thinking dispositions of emergency nurses in Turkey: A cross-sectional study. Hong Kong Journal of Emergency Medicine, 19 (3), 198-203.

Kinicki, A. (2008). Organizational Behavior: Core Concepts. McGraw Hill Irwin: New York.

Kong, L., Liu, Y., Li, G., Fang, Y., Kang, X. and Li, P. (2016). Resilience moderates the relationship between emotional intelligence and clinical communication ability among Chinese practice nursing students: A structural equation model analysis. Nurse Education Today, 4664-68. doi:10.1016/j.nedt.2016.08.028

Kucukguclu, O., and Kanbay, Y. (2011). The relations between critical thinking inclination and clinical success of nursing students. Journal of Anatolia Nursing and Health Sciences, 14 (3), 21-25.

Lanjananda, P., and Patterson, P. G. (2009). Determinants of customer-oriented behaviour in a health care context. Journal of Service Management, 20 (1), 5-32.

Liao, H., and Chuang, A. (2004). A multilevel investigation of factors incluencing employee service performance and customer outcomes. Academy of Management Journal 2004, $47(1), 41-58$.

Lim, L. P. (2016). Moderating Effect of Affective Commitment on the Relationship between Personality Traits, Job Satisfaction and Customer-Oriented Behaviour Among Nurses [Doctor of Philosophy Thesis]. Universiti Teknologi Malaysia, Skudai.

Mahasneh, A. M. M. (2013). Investigation Relationship Between Emotional Intelligence and Personality Traits Among Sample of Jordanian University Students. Cross-Cultural Communication, 9(6), 82-86.

Mangena, A., and Chabeli, M. M. (2005). Strategies to overcome obstacles in the facilitation of critical thinking in nursing education. Nurse Education Today, 25 (4), 291-298.

Matthews, G., Emo, A. K., Funke, G., Zeidner, M., Roberts, R. D., Costa, P. T., Jr. and Schulze, R. (2006). Emotional intelligence, personality, and task-induced stress. Journal of Experimental Psychology: Applied, 12, 96-107.

McCrae, R. R. (2000). Emotional intelligence from the perspective of the five-factor model of personality. In The Handbook of Emotional Intelligence: Theory, Development, Assessment, and Application at Home, School, and in the Workplace, ed. R Bar-On, JDA Parker, 263-76, San Francisco, CA: Jossey-Bass.

McCrae, R. R., and Costa, P. T. (1987) Validation of the Five Factor Model of Personality Across Instruments and Observers. Journal of Personality and Social Psychology, 1, 81-90.

McCrae, R. R., and John, O. P. (1992). An Introduction to the Five-Factor Model and its Applications. Journal of Personality. 2, 175-215.

McCrae, R. R., and Sutin, A. R. (2009). Openness to Experience. Handbook of Individual Differences in Social Behavior, 257-273.

McQueen, A. C. H. (2004). Emotional intelligence in nursing work. Journal of Advanced Nursing 47(1), 101-108.

Miao, C., Humphrey, R. H., and Qian, S. (2017). Are the emotionally intelligent good citizens or counterproductive? A meta-analysis of emotional intelligence and its relationships with organizational citizenship behavior and counterproductive work behavior. Personality and Individual Differences, 16, 144-156. http://dx.doi.org/10.1016/j.paid.2017.04.015 
Mount, M. K., Barrick, M. R., and Stewart, G. L. (1998). The five factor model of personality and performance in jobs that involve interpersonal interaction. Human Performance, $11(2-3), 145-165$.

Myers, I., and Myers, P. (2010). Gifts differing: Understanding personality type: Nicholas Brealey Publishing.

Narver, J. C., and Slater, S. F. (1990). The effect of a market orientation on business profitability. The Journal of marketing, 20-35.

Nawi, N. H., Redzuan, M., and Hamsan, H. (2012). Inter relationship between emotional intelligence and personality trait of educator leaders. International Journal of Academic Research in Business and Social Sciences, 2(5), 223-237.

Nawi, N. H. M., Redzuan, M., Hashmi, S. I., and Din, A. (2015). Big-Five personality traits and its effect on Emotional intelligence among public school personnel in Malaysia. Southeast Asia Psychology Journal, 3, 1-14.

Newness, K., Steinert, J., and Viswesvaran, C. (2012). Effects of personality on social network disclosure: Do emotionally intelligent individuals post inappropriate content? Psychological Topics, 21, 473-486.

Ong, C. H., and Johari, H. (2013). The state of customer-oriented behaviour in the health tourism hospitals in Malaysia. International Journal of Arts and Commerce, 2 (10), 916.

Ong, C. H., and Johari, H. (2014). A conceptual analysis of personality traits and customeroriented behaviour in the health tourism hospitals. International Journal of Caring Sciences, 7 (2), 368-374.

Peccei, R., and Rosenthal, P. (2001). Delivering customer-oriented behavior through empowerment: An empirical test of HRM assumptions. Journal of Management Studies, 38, 831-857.

Petrides, K. V., and Furnham, A. (2001). Trait emotional intelligence: Psychometric investigation with reference to established trait taxonomies. European Journal of Personality, 15, 425-448.

Pettijohn, C., Rozell, E., and Newman, A. (2010). The relationship between emotional intelligence and customer orientation for pharmaceutical salespeople. International Journal of Pharmaceutical and Healthcare Marketing, 4 (1), 21-39.

Poropat, A. E. (2009). A meta-analysis of the five-factor model of personality and academic performance. Psychological Bulletin, 135, 322-338.

Ramachandran, Y., Jordan, P. J., Troth, A. C., and Lawrence, S. A. (2011). Emotional intelligence, emotional labour and organisational citizenship behaviour in service environments. International Journal of Work Organisation and Emotion, 4(2), 136-157.

Robbins, S. P., Judge, T. A., Millett, B., and Jones, M. (2010). OB: The essentials. Pearson Higher Education AU.

Roger, D., and Najarian, B. (1989). The construction and validation of a new scale for measuring emotion control. Personality and Individual Differences, 10, 845-853.

Saklofske, D. H., Austin, E. J., and Minski, P. S. (2003). Factor structure and validity of a trait emotional intelligence measure. Personality and Individual Differences, 34, 10911100.

Saklofske, D. H., Austin, E. J., Rohr, B. A., and Andrews, J. J. W. (2007). Personality, Emotional Intelligence and Exercise. Journal of Health Psychology, 12(6), 937-948.

Sala, F. (2002). Emotional Competence Inventory: Technical manual. Philadelphia, PA: McClelland Center For Research, Hay Group. 
Salgado, J. F. (1997). The five factor model of personality and job performance in the European Community. Journal of Applied Psychology, 82, 30-43.

Saucier, G. (1997). Effects of variable selection on the factor structure of person descriptors. Journal of Personality and Social Psychology, 73(6), 1296-1312.

Schneider, B., and Smith, D. B. (2004). Personality and Organizations. Lawrence Erlbaum Associates, New Jersey, London.

Schutte, N. S., and Malouff, J. M. (2011). Emotional intelligence mediates the relationship between mindfulness and subjective wellbeing. Personality and Individual Differences, 50, 1116-1119. doi: 10.1016/j.paid.2011.01.037

Schutte, N. S., Malouff, J. M., Hall, L. E., Haggerty, D. J., Cooper, J. T., Golden, C. J., and Dornheim, L. (1998). Development and validation of a measure of emotional intelligence. Personality and Individual Diffrences, 25, 167-177.

Serrat, O. (2017). Understanding and Developing Emotional Intelligence. In: Knowledge Solutions. Springer, Singapore. https://doi.org/10.1007/978-981-10-0983-9_37

Shaffer, D. R. (2004). Social and personality development (5th ed.). New York: Wadsworth.

Shih, H., and Susanto, E. (2010). Conflict management styles, emotional intelligence, and job performance in public organizations. International Journal of Conflict Management, $21(2), 147-168$.

Shulman, T., and Hemenover, S. (2006). Is dispositional emotional intelligence synonymous with personality? Self and Identity, 5(2), 147-171.

Simoens, S., Villeneuve, M., and Hurst, J. (2005). Tackling Nurse Shortages in OECD countries. OECD, Paris.

Smillie, L. D., DeYoung, C. G., and Hall, P. J. (2015). Clarifying the relation between extraversion and positive affect. Journal of Personality (in press).

Tam, J. L. M. (2007). Linking quality improvement with patient satisfaction: A study of a health service centre. Marketing Intelligence and Planning, 25 (7), 732-745.

Tang, T., and Tang, Y. (2012). Promoting service-oriented organizational citizenship behavior in hotels: the role of high-performance human resource practices and organizational social climate. International Journal of Hospitality Management, 31(3), 885-895. DOI: 10.1016/j.ijhm.2011.10.007.

Teng, C. C., and Barrows, C. W. (2009). Service orientation: antecedents, outcomes, and implications for hospitality research and practice. The Service Industries Journal, 29 (10), 1413-1435.

Thompson, E. R., and Prendergast, G. P. (2015). The influence of trait effect and the five-factor personality model on impulse buying. Personality and Individual Differences, 76, 216221.

Vakola, M., Tsaousis, I., and Nikolaou, I. (2004). The Role of Emotional Intelligence and Personality Variables on Attitudes toward Organizational Change. Journal of Managerial Psychology, 19, $88-110$.

Wanberg, C. R., and Kammeyer-Mueller, J. D. (2000). Predictors and Outcomes of Proactivity in the Socialization Process. Journal of Applied Psychology, 373-385.

Warwick, J., and Nettelbeck, T. (2004). Emotional intelligence is ...? Personality and Individual Differences, 37, 1091-1100.

Watanabe, S., Tareq, M., and Kanazawa, Y. (2011). When openness to experience and conscientiousness affect continuous learning: A mediating role of intrinsic motivation and a moderating role of occupation. Japanese Psychological Research, 1-14. 
Wiggins, J. S., and Trapnell, P. D. (1997). Personality Structure: The Return of the Big Five. In R. Hogan, J. Johnson and S. Briggs, Handbook of Personality Psychology (pp. 737-765). San Diego: Academic Press.

Winsted, K. F. (2000a). Patient satisfaction with medical encounters a cross-cultural perspective. International Journal of Service Industry Management, 11 (5), 399-421.

Winsted, K. F. (2000b). Service behaviors that lead to satisfied customers. European Journal of Marketing, 34 (3-4), 399-417.

Wortmann, J., Lucas, R. E., and Donnellan, M. B. (2012). Stability and change in the Big Five personality domains: Evidence from a longitudinal study of Australians. Psychology and Aging, 27, 867-874.

Yoon, S. J., Choi, D. C., and Park, J. W. (2007). Service orientation: its impact on business performance in the medical service industry. The Service Industries Journal, 27(4), 37188.

Yusoff, M. B., Esa, A., Pa, M., Mey, S., Aziz, R., and Abdul Rahim, A. (2013). A longitudinal study of relationships between previous academic achievement, emotional intelligence and personality traits with psychological health of medical students during stressful periods. Education for Health, 26(1), 39. http://dx.doi.org/10.4103/13576283.112800

Zee, V. D. K., Schakel, L., and Thijs, M. (2002). The relationship of emotional intelligence with academic intelligence and the big five. European Journal of Personality, 16, 103-125. 